\title{
O cuidado na saúde e na doença: uma perspectiva gestáltica
}

\section{Caring. Health and sickness: a gestalt approach}

\section{Karina Okajima Fukumitsu}

Professora do Curso de Psicologia da Universidade Presbiteriana Mackenzie - São Paulo, SP, Brasil

Doutoranda em Psicologia Escolar e do Desenvolvimento Humano na Universidade de São Paulo/USP - São Paulo, SP, Brasil

\section{Flaviana Cavalcante}

Especializanda em Gestalt-terapia pelo Instituto de Gestalt-terapia de São Paulo/IGSP - São Paulo, SP, Brasil

\section{Marcelo Borges}

Especialista em Gestalt-terapia pelo Instituto de Gestalt-terapia de São Paulo/IGSP - São Paulo, SP, Brasil

\begin{abstract}
Resumo
Este artigo apresenta relações entre a Gestalt-Terapia, cuidado, cura e processos de saúde e doença. O cuidado passa a ser significativo para as pessoas sempre que um encontro genuíno acontece. Considerando que o profissional da saúde é um cuidador, sua relação com o cliente pode ser facilitadora para a instauração de novos sentidos, descobertas existenciais e, eventualmente, um caminho para a cura. Entende-se cura como o processo de retorno ao saudável e ao reconhecimento das potencialidades e possibilidades humanas.
\end{abstract}

Palavras-chave: Gestalt-terapia, Cuidado, Saúde e doença.

\begin{abstract}
This article presents the relationship of Gestalt therapy, caring, healing, and the process of health and sickness. Caring turns out to be meaningful to people as the genuine encounter happens. Considering that any healthcare professional is a caretaker, the relationship with the client helps the disclosure of meanings, existential findings and a way to cure. We understand cure as the return to heal and to the recognition of potentialities and possibilities of the human being.
\end{abstract}

Keywords: Gestalt-therapy, Caring, Health and sickness.

Nesta fuga frenética para alcançar tudo que for possível na vida, acabamos por nos comportar como turistas desesperados: fotografando tudo, mas não enxergando nada (ZINKER, 2007, p.21). 
A ação de cuidar exige um olhar atento e está inserido numa dinâmica dialética entre o cuidador e aquele que é cuidado. Neste sentido, cuidar possibilita a presença do potencial de saúde que pode emergir neste contexto.

Entendemos que o profissional de saúde que se dedica a outro ser humano é considerado um cuidador - não no sentido de fazer por, mas, sim, de fazer com o outro. Diferença sutil, mas merecedora de atenção e reflexão, principalmente pela concordância com o pensamento existencial que advoga que o ser-com apresenta-se como significado ontológico das relações interpessoais e como constitutivo da existência humana.

Este artigo apresenta uma reflexão sobre o cuidado na perspectiva da abordagem Gestáltica considerando dois temas fundamentais:

- o paradoxo entre processos de saúde e doença;

- o cuidado como facilitador nas relações interpessoais e como caminho para o resgate de processos saudáveis.

Azevedo e Dimenstein (2008, p. 664), em seu artigo "O acompanhamento terapêutico no cuidado em saúde mental", refletem sobre o envolvimento e o desgaste do cuidador dos portadores de transtornos mentais (PTM) e convidam a pensar sobre o paradoxo entre fazer por e fazer com:

As dificuldades ao cuidado diário são reportadas com veemência aos momentos de crises dos PTM em que a autonomia deste (corroborada em seus relatos) é comprometida e, para tanto, convoca o cuidador a responsabilizar-se pelo asseio, ministrar a medicação, conduzi-los até - ambulatório etc. Para os familiares, a sobrecarga é bastante evidente, expressa sob diferentes aspectos. Do ponto de vista emocional, a demanda por uma atenção contínua (PTM estando ou não em crise) dota o cuidador de uma responsabilidade exacerbada, que acomete seu bem-estar psíquico e requer uma abdicação de suas atividades de lazer $[\ldots]$

É importante ressaltar que, quando se faz por, o compromisso está vinculado ao ato de ajudar e de suprir as necessidades e não necessariamente à relação. Hycner e Jacobs (1997) mencionam que "A relação é uma parte inerente do nosso ser, não um adendo posterior" (p.120). Enxergar o outro em sua alteridade representa mais que ver o outro; significa criar condições fundamentais para que o cuidado apareça. Dessa maneira, o cuidado emerge apenas quando a existência de alguém adquire significado para as pessoas envolvidas, ou seja, o cuidador e aquele que está sendo cuidado. Assim, o profissional passa a participar das escolhas, do destino, dos desejos, sofrimentos e das conquistas e, simultaneamente, a pessoa cuidada apresenta disponibilidadde para compartilhar. Cuidado, portanto, significa também compreender o outro como um ser humano em busca de conhecimento de seus processos, que muitas vezes transcendem o próprio sintoma que ele expressa. Desta forma, 
saúde e doença podem estabelecer um diálogo interno em busca do reconhecimento do sentido que a pessoa faz de sua própria condição de apresentar-se através da doença.

Além disso, cuidar significa responsabilizar-se pela disponibilidade de testemunhar, acompanhar e compartilhar o caminho do outro, constituindo-se numa atitude amorosa, que "implica 'entrega' ou disponibilidade para relacionar-se, conviver com o desconhecido e o mutante, e a capacidade de valorizar o conhecido e nele se aprofundar" e é "concebido como o compartilhar, entre dois seres íntegros e diferenciados" (CARDELLA, 1994, p. 19-20).

Desse modo, a idéia de um processo saudável apresenta-se como uma forma fluida de se colocar no mundo no momento em que o ser humano está consciente da maneira como vivencia e reconhece suas questões pessoais e interpessoais, enfim, como vivencia a singularidade de "ser".

Apesar de destacarmos a importância do ato de cuidar, pode-se perguntar até que ponto o cuidado cura? A resposta para a questão direciona-se primeiramente para a frase de Cancello (1991, p. 51), que aponta: "[...] a cura foge, ao ser buscada. É um fenômeno decorrente desse encontro humano muito especial entre terapeuta e cliente, em seu espaço próprio" e, segundo, para a apresentação dos conceitos fundamentais na atuação do gestalt-terapeuta, que são o contato, o encontro e a ampliação de awareness.

Na perspectiva gestáltica, saúde e doença não são conceitos estáticos e podem ser entendidos como formas do organismo total tentar dar um sentido peculiar à sua existência, na busca de trocas constantes com o contexto no qual está inserido. Fritz Perls (1981) acreditava que a pessoa relaciona-se com o ambiente e, nas tentativas de adaptação, pode cristalizar seus modos de relação ou flexibilizá-los de formas criativa. Assim, saúde e doença tornam-se processos dinâmicos, possíveis e caracterizados pela interação.

A Gestalt-Terapia aponta a necessidade da presença do psicoterapeuta no processo que, de acordo com Hcyner e Jacobs (1997) não significa estar somente de corpo presente, mas, sim, "implica trazer para interação a plenitude de nós mesmos" (p.78). Dessa maneira, o aspecto mais importante a ser considerado é a relação entre psicoterapeuta e cliente, pessoas singulares, com tempos diferentes, cabendo ao profissional da saúde acompanhar "pacientemente" o tempo do cliente, em direção a um possível encontro, advindo do enriquecimento do contato.

\section{A construção do Ser Cuidador}

Podemos compreender o cuidado como uma condição existencial e, de certa forma, como um processo inerente às relações constituídas 
entre os profissionais de saúde e as pessoas que os buscam, visando minimizar seu sofrimento. Conceituar a saúde e a doença provoca certo incômodo, justamente pela crença de que não se trata apenas de conceitos, mas, sim, de processos que emergem de históricos singulares. Medeiros (2005) integra os processos existenciais e alguns campos de conhecimento para a compreensão da saúde, ao mencionar que "ocorrem transportes, traduções, interpretações, isto é, formas de objetivação que, ao darem sentido a determinados fenômenos, produzem modos de nos relacionarmos conosco" ( $p$. 264). Desmistificando a ideia de que o profissional da saúde é curandeiro e que seu objetivo é a cura, percebe-se cada vez mais uma objetificação do ser humano no sentido de torná-lo produtivo. Isto posto, a errônea premissa seria: "é alguém somente quem produz, e doentes não produzem. Logo, se a doença for extinta existirá a possibilidade de produzir mais produtores". Ocorre um viés no conceito de saúde para uma vertente econômica, ou seja, o ser humano com saúde é aquele que produz e, em contrapartida, o ser humano doente é aquele que não pode produzir. É necessário extirpar, extinguir a doença para que a condição de "ser humano produtor" retorne. Porém, simultaneamente a esta premissa, um cenário econômico marcado pelo capitalismo muitas vezes necessita também de produzir o doente para a manutenção de certos segmentos de negócio, tais como a indústria farmacêutica que retroalimenta este sistema, transformando-o num ciclo paradoxal. Vale ressaltar também que, muitas vezes, a saúde é compreendida como adequação às normas e condutas vigentes numa determinada cultura, desconsiderando o sofrimento subjetivo daquele que a ela se acomoda.

Com a crescente demanda por produção, a distorção mercantilista mostra-se pouco eficaz, direcionando o conceito de saúde para outro aspecto, também importante, que é apontado por Coelho (2002, p. 316) em seu artigo "Conceitos de saúde em discursos contemporâneos de referência científica", quando o autor aborda a pobreza do ponto de vista epistemológico acerca do conceito de saúde. "Ganha força, então, a ideia de promover a saúde, e não apenas de curar a doença [...]". Juntamente com a noção de promoção de saúde, ganha destaque a figura do profissional desta área.

No entanto, a questão aqui proposta pretende enfatizar a possibilidade de fazer com, considerando-se o contexto no qual ambos, psicoterapeuta e cliente, estão inseridos. Dessa maneira, no momento em que se preconiza que parte do retorno ao saudável depende das disponibilidades, tanto do profissional quanto do cliente, cabe ampliar a reflexão para os casos de atendimentos em instituições, nas quais os profissionais da saúde devem exercitar sua 
disponibilidade para com o outro e, ao mesmo tempo, articular sua práxis com as demandas institucionais.

É necessário, portanto, compreender as características das instituições, ou seja, o que é instituído, criado e estabelecido por essa instituição. O foco na relação com o cliente, porém, deve ser a preocupação primordial. Infelizmente, os aspectos anteriormente destacados, que dificultam o cuidado e a disponibilidade do profissional, não aparecem exclusivamente no contexto de instituições públicas, mas também estão presentes na prática clínica. Basta verificar a grande fila de espera para atendimento psicológico nas universidades privadas e instituições que mantêm atendimentos gratuitos com formato ou em esquema de clínica solidária.

Muitas vezes em função do grande número de pessoas a serem atendidas, o formato do atendimento tem um prazo determinado, o que contraria a necessidade de assegurar ao cliente que o processo de desenvolvimento acontecerá no seu ritmo e tempo singulares. Novamente, o profissional de saúde deve considerar o contexto no qual está inserido, pois esse é o "lugar" onde sua relação com o cliente ocorrerá. Podemos questionar também o conceito de saúde e doença atribuído neste contexto para que tais idéias não sejam tratadas como produto, produção ou estados vitrificados, onde 0 profissional que pretende atuar em prol da saúde não se transforme num mero instrumento de "contenção" da doença, sem refletir ou desenvolver um pensamento crítico em relação a estas intervenções. Todas as variantes supracitadas estão em constante transformação, o que torna a reflexão sobre o cuidado um processo e um questionamento constante. Sendo assim, não seria adequado restringir o significado de saúde e doença, uma vez que saudável também é entendido como possibilidade de conceber saúde e doença de forma integrada. Dessa maneira, o cuidado envolve, fundamentalmente, a relação humana e o modo pelo qual o cliente experiencia, de forma singular, seu ser-no-mundo e o espaço que se abre para o contato com a sua condição.

Para Ayres (2007, p. 43) é necessário considerar o conceito de saúde e doença de uma forma abrangente, pois reduzir sua compreensão a polaridades é "tão limitante para a adequada compreensão dessas duas construções discursivas e das práticas a elas relacionadas, quanto negar as estreitas relações que guardam uma com a outra na vida cotidiana".

A polarização de saúde e doença pode levar à polarização da própria relação psicoterápica, quando o gestalt-terapeuta seria o detentor da possibilidade de saúde e o cliente seria o doente. O que, nesse caso, induziria a se compreender equivocadamente que saúde é ausência de doença, concepção inversa a que estamos trazendo aqui.

Entre os gestalt-terapeutas a idéia de cura não é uma meta ou um estado a ser atingido. Considerando a base fenomenológico- 
existencial desta abordagem, cuidar constitui-se num processo construído entre duas pessoas, fundamentado numa relação de confiança que é também elaborada num tempo e espaço indeterminados. No cuidado, existe a permissão para se lapidar as lentes pelas quais podemos transcender o objeto previamente conhecido, permanecendo com o fenômeno da relação. Portanto, é pela disponibilidade do psicoterapeuta e do cliente, ambos seres singulares, que o encontro é possível. É por meio do encontro que se configura a relação psicoterápica. O que vai ao encontro de Polster (2001, p.114), eminente gestalt-terapeuta, quando ele descreve que: “O contato não é apenas reunião ou intimidade. Ele só pode acontecer entre seres separados, que sempre precisam ser independentes e sempre se arriscam a ser capturados na união". Nesse contexto, a possibilidade do encontro emerge. Não há garantias de o encontro ocorrer, tampouco é possível buscá-lo, pois a disponibilidade para estar-com é que favorece o encontro.

A relação psicoterapêutica é, portanto, uma relação intersubjetiva, pela qual a diferença entre os dois seres se faz presente. Ao gestaltterapeuta é concedida a tarefa do cuidado. Merighi (2002, p. 158) afirma que o cuidado está vinculado com a compreensão, onde a relação "[...] deve ser simétrica: ouvindo o outro ouvindo a nós mesmos, cuidando do outro, cuidando de nós mesmos".

A presença do psicoterapeuta proporciona ao cliente confirmações existenciais, ou seja, quando o gestalt-terapeuta permanece presente nessa relação, oferece a possibilidade fértil para que o cliente possa ressignificar suas necessidades. Esta idéia é confirmada, inclusive, por terapeutas de outra orientação teórica, como Yalom (2008, p. 178), ao mencionar: "Os pacientes transformam a estima do terapeuta em autoestima pessoal". Com efeito, a fluidez constitui uma presença saudável. Ayres (2007, p. 58) aponta que: “É preciso também ouvir o que o outro, que demanda o cuidado, mostra ser indispensável que ambos saibamos para que possamos colocar os recursos técnicos existentes a serviço dos sucessos práticos almejados". É o psicoterapeuta quem, por todo o seu referencial teórico e vivencial - acompanha o cliente em seu processo na busca da saúde possível em seu momento e contexto pessoal.

Como dito anteriormente, a presença do terapeuta possibilita 0 engajamento do cliente, inclusive na responsabilidade de seu processo de saúde e de doença, tornando, na maioria das vezes, possível para o cliente suportar os sintomas advindos do adoecimento. Coelho (2002, p. 322) afirma: “Enquanto a saúde se caracteriza pela abertura às modificações e pela instituição de novas normas de saúde, o patológico corresponde à impossibilidade de mudança e à obediência irrestrita às normas".

Sarriera (2003, p. 89) aponta para a complexidade da questão quando considera a existência de paradigmas diversos acerca do 
conceito de saúde e isso se deve a um questionamento da ciência. E alerta que especificamente no campo da psicologia é necessário "repensar o objeto complexo saúde-doença-cuidado, levando[-se] em consideração as bases epistemológicas que o sustentam".

Como define o Dictionary of Psychology (2001, p.171), cura significa o retorno à saúde (a returne to health). Sendo assim, segundo a perspectiva que trazemos aqui, acreditamos que a cura está no encontro e o cuidado, na relação. A presença é uma manifestação do cuidado e a cura uma expressão do encontro, uma manifestação do vivido. Spangenberg (2007) afirma que: "É através do espelho dos olhos de quem nos ama que descobrimos nossa alma" (p. 24). O cuidado é importante quando a ênfase está no encontro de dois seres humanos que se preocupam e ocupam um espaço conjunto e constroem um lugar para o entre.

O objetivo principal na psicoterapia gestáltica é a ampliação da awareness. Yontef (1998) postula que "Awareness é uma forma de experienciar. É o processo de estar em contato atento com o evento mais importante do campo indivíduo/ambiente. Torna-se imprescindível para o profissional da saúde não fixar sua atenção no conceito de saúde ou doença exclusivamente, mas observar a forma como o cliente percebe suas vivências. Desta forma, a possibilidade de cura emerge quando o cliente compreende sua experiência de reconhecimento tanto daquilo que ele pode nomear como saúde quanto de doença. Perceber a doença, como determinante da identidade do cliente, significa não cuidar, pois ele ficará limitado a um único aspecto, tornando o cuidado uma ação um ato disfuncional. Hycner e Jacobs (1997, p. 39) destacam a postura do psicoterapeuta diante dessas questões. O conceito de saúde, de doença ou de psicopatologia está presente, porém o foco está na relação com o cliente, e o psicoterapeuta "suspende" esses conceitos e permanece no contato, na possibilidade de encontro, ou seja, no cuidado. É necessário, ao menos momentaneamente, que o terapeuta tente "[...] suspender todos os seus vieses pessoais, conhecimento geral sobre pessoas, sobre psicopatologias e categorias de diagnóstico [...]", pois, desse modo, está aberto e presente, "fazendo surgir a sensação de se admirar diante da extrema singularidade e humanidade da pessoa que tem diante de si" (HYCNER; JACOBS, p. 40).

O gestalt-terapeuta percebe o diagnóstico de uma doença como uma sabedoria compreendida em fluxo, ou seja, é necessário conhecer o cliente no processo para, depois, conhecer seu sintoma. O sintoma é o sinalizador daquilo que não está bem no processo. É um mapeamento, uma orientação e, não, o território. O diagnóstico representa a posição, o lugar que a pessoa ocupa no mundo e o momento em que está. Contudo, não devemos perder de vista o que o constitui. Entende-se a doença como um estado no qual o fluxo em 
direção à mudança, novidade e atualização está interrompido. A Gestalt-terapia ressalta a assimilação da novidade como facilitador do desenvolvimento. Em outras palavras, cada situação nova exige, do ser humano, novas respostas e atualizações, pois surgem diversas sensações provocadas pelas imprevisibilidades do cotidiano. Nesse sentido, a doença exige uma reorganização. Um corpo desorganizado é expressão de uma alma desorganizada e é, pelo cuidado, pela manifestação de preocupação, relação, confirmação e de amor que o profissional pode revelar sua disponibilidade de ocupar-se previamente das questões do outro. Perls (1977, p.77) salienta que

O organismo sadio se reorganiza com todas as suas potencialidades para a gratificação das necessidades primordiais. I mediatamente ao realizar uma tarefa, esta volta [-se] para o fundo e permite que a necessidade que neste intervalo se tornou mais importante, chegue ao primeiro plano.

Como o foco da Gestalt-terapia está na relação, em nenhum momento se fala que o retorno à saúde acontece quando os sintomas desaparecem. Medeiros (2005, p.264) alerta que:

Assim, quando a saúde é definida como uma questão integral, plural, na ânsia de integrar, de tornar o sujeito indivisível, completo, não se está agindo sobre o indivíduo, mas sobre a relação, as ações que ele estabelece consigo e os outros em termos de cuidados e atenção integral".

O gestalt-terapeuta é um profissional que tem, por princípio, a crença nas potencialidades do ser humano, pelo fato de que este é concebido como ser em busca do saudável, ou seja, passível de ser criativo e flexível, que pode ter uma direção para o crescimento. O gestaltterapeuta não é responsável pelo cliente, pois não responde pelo cliente, mas juntamente com ele busca formas de desenvolver as suas possibilidades, ou seja, o desenvolvimento da responsabilidade individual. E isso o torna um privilegiado, por ser escolhido para acompanhar o cliente em sua jornada. Sarriera (2003, p. 92) reflete que

[...] questionamentos vêm sendo realizados a respeito da compreensão das doenças, os quais enfatizam que estas não devem ser unicamente extirpadas, mas sim compreendidas em relação ao contexto no qual surgem e se desenvolvem, respeitando a pessoa e seu ambiente.

Adoecimento não significa paralisia ou incapacidade. Sintomas não precisam desaparecer para que o retorno ao estado saudável aconteça. O não saudável é a impossibilidade de atualizar a maneira de satisfazer as necessidades, é a cristalização, a estagnação em um determinado momento, o que pode transformar respostas conhecidas em anacrônicas, fazendo com que percam a função.

Dessa maneira, o cuidado é um processo árduo, pois exige constantemente: 
1. a confirmação existencial tanto do profissional quanto do cliente;

2. a compreensão do contexto e das questões instituídas;

3. a compreensão dos estados saudáveis e dos adoecimentos e a relação com a singularidade do cliente;

4. a noção do compartilhar como forma atuante no processo relacional;

5. a descoberta, com o cliente, das possibilidades para enriquecimento das formas de contato e de atualização das relações humanas.

Pokladek (2004, p. 257) indica que "Cuidar constitui-se no exercício da pré-ocupação em celebrar um acontecer", é uma forma de perceber o outro e a maneira de coexistir, permanecendo abertos para criação de nossas possibilidades. Essa postura pressupõe possibilidade de atualização, e Spangenberg (2007, p. 22) esclarece as dificuldades dessa atualização quando cita:

Não somos o produto passivo das circunstâncias de nosso passado. $O$ importante não é o que nos aconteceu, e sim como reagimos [diante dos] acontecimentos de nossa vida [...]; o que nos diferencia como seres humanos não é o conteúdo de nossas histórias pessoais, e sim a forma como reagimos a elas.

Podemos finalizar esta reflexão, destacando a importância da consciência fundamental que o profissional de saúde deve desenvolver sobre a maneira como compreende saúde e doença, pois seu modo de pensar orientará sua ação, principalmente no que diz respeito ao cuidado e à necessidade de se tornar disponível para o outro. Assim como Kübler-Ross (2005, p. 16) afirma "Amar é se dar, e toda doação só é significativa se for em benefício mútuo. Entendemos que o cuidado é um ato de amor por si e pelo outro. Sendo assim, o preparo para se tornar um cuidador requer energia, prontidão, confiança e disponibilidade para solidificar essa relação. Além disso, cuidar é também assumir riscos, pois, apesar de buscar atuar na relação, acreditando no potencial de saúde daquele que está sendo cuidado, o profissional da saúde que cuida precisa estar despojado da onipotência da cura, conhecendo seus limites pessoais e respeitando as escolhas do ser humano que são imprevisíveis e carregadas de significados próprios, peculiares à trajetória de cada um. Afinal, responsabilidade neste contexto deve envolver a relação onde o cuidador e aquele que é cuidado formam uma totalidade e são afetados mutuamente. Cuidar é, sobretudo , um desafio, onde somos frequentemente "provocados" a rever nossas possibilidades e limites, sem invadir ou ser invadido, mantendo a fronteira de contato para viabilizar a saúde possível no contexto no qual a relação se desenvolve. 


\section{Referências Bibliográficas}

AZEVEDO, T.; DIMENSTEIN, M. O acompanhamento terapêutico no cuidado em saúde mental. Estudos e Pesquisas em Psicologia, UERJ, Rio de Janeiro, v. 8 n. 3, p.658-671, $2^{\circ}$ semestre de 2008. Disponível em: <http://www. revispsi.uerj.br/v8n3/sumariov8n3.html>. Acesso em: 12 de janeiro de 2009.

AYRES, J. R. C. M. Uma concepção hermenêutica de saúde. Physis, Rio de Janeiro, v. 17, n. 1, p. 43-62, abril de 2007. Disponível em: $<$ http://www. scielo.br/scielo.php?script=sci_arttext\&pid=S0103-

73312007000100004\&lng=pt\&nrm=iso>. Acesso em: 19 de dezembro de 2008.

CANCELLO, L. A. G. O fio das palavras: um estudo de psicoterapia existencial. São Paulo: Summus, 1991.

CARDELLA, B. H. P.o amor na relação terapêutica: uma visão gestáltica. São Paulo: Summus, 1994.

COELHO, M. T. A. D.; ALMEIDA FILHO, N. de. Conceitos de saúde em discursos contemporâneos de referência científica. História, ciência e Saúde - Manguinhos [online]. v. 9, n. 2, p. 315-333, 2002. Disponível em:

$<$ http://www.scielo.br/scielo.php?script=sci_arttext\&pid=S0104-

$59702002000200005 \& \operatorname{lng}=p t \& n r m=i s o>$. Acesso em 19 de dezembro de 2008.

DICTIONARY OF PSYCHOLOGY. New York: Penguin Books, 2001.

HCYNER,R.; JACOBS; L. Relação e cura em Gestalt-terapia. São Paulo: Summus, 1997.

KÜBLER-ROSS,E. Viver até dizer adeus. São Paulo: Pensamento, 2005.

MEDEIROS, P. F.; BERNARDES, A. G.; GUARESCHI, N. M. F.. O conceito de saúde e suas implicações nas práticas psicológicas. Psic.: Teor. e Pesq., Brasília, v. 21, n. 3, p. 263-269, dezembro de 2005. Disponível em: $<$ http://www.scielo.br/scielo.php?script=sci_arttext\&pid=S0102-

$37722005000300002 \& \operatorname{lng}=$ pt\&nrm=iso $>$. Acesso em 20 de dezembro de 2008.

MERIGHI, M. A. B. Cuidado: enfermagem e fenomenologia. In: CASTRO, D. S. P. de et al. Existência e Saúde. São Bernardo do Campo: UMESP, 2002.

NOGUEIRA, R. P.. A saúde da Physis e a saúde do Dasein em Heidegger. Physis, Rio de Janeiro, v. 17, n. 3, p. 429-450, 2007. Disponível em: $<$ http://www. scielo.br/scielo.php?script=sci_arttext\&pid=S010373312007000300002\&lng=pt\&nrm=iso>. Acesso em 19 de Dezembro de 2008.

PERLS, F.S. I sto é Gestalt. São Paulo: Summus, 1977. 
PERLS, F.S. A abordagem gestáltica e a testemunha ocular da terapia. Rio de Janeiro, Guanabara, 1981.

POKLADEK, D. S. et al. A Fenomenologia do cuidar: prática dos horizontes vividos nas áreas da saúde, educacional e organizacional. São Paulo: Vetor, 2004.

POLSTER; E.; POLSTER, M. Gestalt-terapia integrada. São Paulo: Summus, 2001.

SARRIERA, J. C. et al. Paradigmas em psicologia: compreensões acerca da saúde e dos estudos epidemiológicos. Psicol. Soc., Porto Alegre, v. 15, n. 2, p. 88-100, Dezembro de 2003. Disponível em $<$ http://www. scielo.br/scielo.php?script=sci_arttext\&pid=S0102-

71822003000200007\&lng=pt\&nrm=iso>. Acesso em 19 de dezembro de 2008.

SPANGENBERG, A. Gestalt Terapia: Um caminho de volta para casa.Campinas: Editora Livro Pleno, 2007.

ZINKER, J. Processo criativo em Gestalt-terapia. São Paulo: Summus, 2007.

YALOM, I. D. De frente para o sol: como superar o terror da morte. Rio de Janeiro: Agir, 2008.

YONTEF, G. Processo, Diálogo e Awareness: ensaios em Gestaltterapia. São Paulo: Summus, 1998.

\section{Endereço para correspondência}

Karina Okajima Fukumitsu

Avenida Fagundes Filho, Ed. Austin Office Center, 145 sala 96, CEP 04304-010, Vila Monte Alegre, São Paulo-SP, Brasil

Endereço eletrônico: karinafukumitsu@gmail.com

Flaviana Cavalcante

Rua Dona Inácia Uchoa, 69, CEP 04110-020, Vila Mariana, São Paulo-SP, Brasil Endereço eletrônico: flavianacav@uol.com.br

Marcelo Borges

Avenida Lins de Vasconcelos, 3046, CEP 04112-002, Vila Mariana, São Paulo-SP, Brasil

Endereço eletrônico: mborg@uol.com.br

Recebido em: 30/01/2009

Aceito para publicação em: 01/03/2009

Editor responsável: Laura Cristina de Toledo Quadros 